\title{
Study of kaolin for synthesis of Aluminum Chloride
}

\author{
Krishna Kumar, Omprakash Sahu \\ Department of Chemical Engineering, KIOT, Wollo University, Ethiopia
}

Email address:

ops0121@gmail.com(K. Kumar)

\section{To cite this article:}

Krishna Kumar, Omprakash Sahu. Study of Kaolin for Synthesis of Aluminum Chloride. American Journal of Chemical Engineering. Vol. 1, No. 2, 2013, pp. 36-39. doi: 10.11648/j.ajche.20130102.11

\begin{abstract}
Aluminum chloride enhanced polyacrylamide ( $\left.\mathrm{AlCl}_{3}-\mathrm{PAM}\right)$ hybrid polymer has been synthesized in this study. Aluminium chloride was synthesized with polyacrylamide via free radical solution polymerization to fabricate inorganicorganic hybrid polymer $\left(\mathrm{AlCl}_{3}-\mathrm{PAM}\right)$. A redox initiation system - $\left(\mathrm{NH}_{4}\right)_{2} \mathrm{~S}_{2} \mathrm{O}_{8}$ and $\mathrm{NaHSO}_{3}$ was used to initiate the polymerization at $50^{\circ} \mathrm{C}$ in aqueous medium. Fourier Transform Infrared Spectrometer (FT-IR) was used to characterize aluminium chloride-polyacrylamide hybrid polymer by determining its functional groups exist in the hybrid polymer chain. Inorganic aluminium chloride salt was incorporated into the polyacrylamide to enhance the aggregation ability at kaolin particle interface. A physico-chemical method which is flocculation was used in this study to flocculate kaolin suspension. The effect of $\mathrm{pH}$ on the flocculation of kaolin suspension was studied between $\mathrm{pH} 5$ to 7.5 . The result showed the aluminium chloride-polyacrylamide $\left(\mathrm{AlCl}_{3}\right.$-PAM) hybrid polymer was able to remove $>99 \%$ of turbidity at $\mathrm{pH} 6.5$ using 5 $\mathrm{mg} / \mathrm{L}$ of dosage.
\end{abstract}

Keywords: Aluminum Chloride, Flocculation, Kaolin, Polyacrylamide

\section{Introduction}

Coagulation-flocculation process has been widely used in the wastewater treatment to destabilize colloids in the wastewater. Coagulation decreases and neutralizes the surface charge of suspended particles by using inorganic salts such as aluminium and ferric salts [1]. Flocculation plays a major role as well in the fate and transport of contaminants in aquatic environments by bringing the aggregated flocs to form large agglomerates in the presence of polymers [1, 2]. Various flocculants have been developed in the recent years; inorganic flocculants, organic flocculants and composite as well as hybrid flocculants. In view of the superior efficiency of the hybrid flocculants compared to conventional inorganic flocculants, and its lower cost compared to the organic flocculants, hybrid flocculants have been extensively studied and applied to water and wastewater treatment system recently [3].

There are two ways to enhance the effectiveness of conventional flocculants increasing the proportion of the most efficient species in their original composition or adding some other components to produce new composite flocculants [4]. The main objective of both methods is to enhance the aggregating power of the materials. Therefore, it is logical to combine inorganic salt with organic flocculating polymer which will strengthen the aggregating power. These inorganic-organic hybrid polymers become an attractive material in wastewater treatment due to their high performance [4, 5]. The synergism effect of combining two components in one material is desirable in the operation of the wastewater treatment facilities, since it will require only one unit operation which is flocculation instead of the conventional coagulation-flocculation system. The reduction of operating time as a consequence of application of this hybrid polymer in a single operation is favorable to industries that produce a large volume of wastewater discharge.

In this study, aluminium chloride-polyacrylamide $\left(\mathrm{AlCl}_{3}-\mathrm{PAM}\right)$ hybrid polymer was synthesized via free radical solution polymerization. FT-IR was used to characterize the hybrid polymer. The flocculation activity on kaolin suspension was studied to determine its optimal operating conditions.

\section{Method}

\subsection{Materials}

Acrylamide ( $>98 \%$ purity) was obtained from Fluka, whereas aluminium chloride ( $>98.5 \%$ purity) was obtained 
from Systerm. Ammonium persulphate (AR, System) and sodium hydrogen sulphite (GR, Acros Organics) were used as redox initiators.

\subsection{Synthesis of Hybrid Polymer}

A $500 \mathrm{~mL}$ three-necked flask equipped with a condenser, water bath stirrer, and a rubber septum cap was set up for the polymerization. Temperature was controlled at $50^{\circ} \mathrm{C}$. $1.0 \mathrm{M}$ of acrylamide ( $71.08 \mathrm{~g}$ in $100 \mathrm{~mL}$ of deionized water) was thoroughly stirred and purged with nitrogen gas for 30 minutes to deoxygenate the reaction medium before polymerization took place. $2 \times 10^{-5} \mathrm{M}$ of ammonium persulphate and $5 \times 10^{-6} \mathrm{M}$ of sodium hydrogen sulphite were used as redox initiator to initiate the polymerization $[5,6]$. The polymerization process took 2 hours, an equivalent mole ratio of aluminium chloride was then added into the flask and the mixture was blended under nitrogen atmosphere for 4 hours until it was homogenous. The $\mathrm{AlCl}_{3}$-PAM hybrid polymer obtained was in a gel form and it was precipitated with acetone to remove nonreacted acrylamide. The hybrid polymer was then vacuum dried and ground into powder.

\subsection{Fourier Transform Infrared (FT-IR) Spectra Analysis}

The chemical compositions of hybrid polymers were determined using Avatar 360 FT-IR spectrophotometer. $\mathrm{AlCl}_{3}$-PAM hybrid polymers were prepared into platelets with potassium bromide. The samples were tested after completion of the blank spectrum scanning. The FT-IR equipment was operated with a resolution of $4 \mathrm{~cm}^{-1}$ and scanning range from 4000 to $400 \mathrm{~cm}^{-1}$.

\subsection{Kaolin Suspension Flocculation}

$\mathrm{AlCl}_{3}$-PAM hybrid polymer was used to flocculate a kaolin suspension. $1.5 \mathrm{~g}$ of kaolin was prepared in $5 \mathrm{~L}$ of distilled water. The solution $\mathrm{pH}$ was adjusted using $0.1 \mathrm{M}$ $\mathrm{HCl}$ and $0.1 \mathrm{M} \mathrm{NaOH}$. Flocculation was carried out using a standard jar test apparatus. The $\mathrm{AlCl}_{3}-\mathrm{PAM}$ hybrid polymer solutions were then added into beakers that contained kaolin suspension to initiate flocculation. The kaolin suspension was mixed at a rapid speed of $200 \mathrm{rpm}$ for $3 \mathrm{~min}$ and at a slow mix of $100 \mathrm{rpm}$ for $6 \mathrm{~min}$. Flocs were formed and allowed to settle for $30 \mathrm{~min}$. The turbidity of the supernatant was measured with a HACH 2100P turbidity meter. Table 1 shows characteristics of the kaolin suspension.

Table 1. Characteristics of the kaolin suspension

\begin{tabular}{cc}
\hline Parameters & Value \\
\hline Turbidity (NTU) & $366-422$ \\
$\mathrm{pH}$ & $3.49-4.29$ \\
\hline
\end{tabular}

Turbidity reduction was calculated according to:

Turbidity reduction $(\%)=$ $\frac{\text { Initial Turbidity }- \text { Final Turbidity }}{\text { Initial Turbidity }} \times 100 \%$

\section{Results and Discussion}

\subsection{Fourier Transform Infrared (FT-IR) Spectra Analysis}

Compositional and functional group of $\mathrm{AlCl}_{3}-\mathrm{PAM}$ were determined by FT-IR spectrophotometer. The FT-IR spectra in Figure 1 show the peaks of $\mathrm{AlCl}_{3}$-PAM hybrid polymer. The functional groups, $-\mathrm{NH}_{2}$ aromatic amine(S), primary amine $(\mathrm{m})$ amides $(\mathrm{m})\left(3520-3320 \mathrm{~cm}^{-1}\right)$, primary amide(s) $\left(1680-1620-\mathrm{CO}-\mathrm{NH}_{2}\left(1420-1400 \mathrm{~cm}^{-}\right.\right.$ $\left.{ }^{1}\right), \mathrm{CH}_{2}=\mathrm{C}-\mathrm{R}-\mathrm{R}$ 'cm $\left(900-875 \mathrm{~cm}^{-1}\right), \mathrm{C}-\mathrm{Cl}\left(760-510 \mathrm{~cm}^{-1}\right)$ from the $\mathrm{AlCl}_{3}$-PAM hybrid polymer are observed in the spectra. Hence, elucidation of FT-IR spectra confirms that the $\mathrm{AlCl}_{3}-\mathrm{PAM}$ hybrid polymer is successfully synthesized and the $\mathrm{AlCl}_{3}$-PAM hybrid polymer forms an inorganicorganic complex and it is consistent with the functional group that needed for flocculation in the subsequent study.

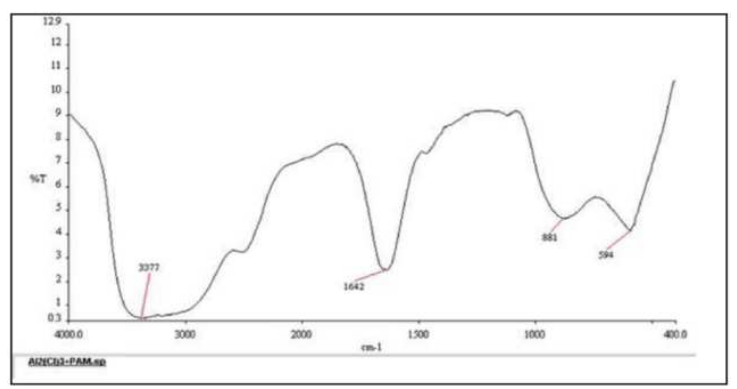

Fig 1. FT-IR spectra for $\mathrm{AlCl}_{3}-\mathrm{PAM}$ hybrid polymer

\subsection{Flocculation of kaolin suspension}

\subsubsection{Effect of $\mathrm{pH}$}

Effective kaolin suspension flocculation only occurs within a specific $\mathrm{pH}$ range using different type of flocculants. Hence, $\mathrm{pH}$ plays a vital role in determining the efficiency of kaolin suspension turbidity reduction. Figure 2 shows the effect of $\mathrm{pH}(5.0-7.5)$ on turbidity reduction. The turbidity reduction increase as the $\mathrm{pH}$ increases from 5.0 to 6.5. At $\mathrm{pH}$ 6.5, it gives the best flocculation efficiency which is $99.9 \%$. The $\mathrm{AlCl}_{3}$-PAM hybrid polymer becomes an ionized state when it was introduced into the kaolin suspension. The ionized $\left[\mathrm{Al}^{3+} \cdot 3 \mathrm{Cl}^{-}\right]-\mathrm{PAM}$ hybrid polymer will stimulate flocculation by neutralization and stabilization of residual negative charges of kaolin and forming bridges to bind them together [7].

Statistical analysis namely ANOVA has been used to compare the effect of $\mathrm{pH}$ in reducing turbidity. One-way ANOVA procedure depicts a one-way analysis of variances for a quantitative dependent variable by a single factor (turbidity reduction) and it was used to test the hypothesis means of the turbidity reduction [8]. The oneway ANOVA test was found to have a significant difference $(\mathrm{p}<0.05)$ between $\mathrm{pH}$ as shown in Table 2 . 
Hence, $\mathrm{pH}$ is concluded to have a significant effect in determining the turbidity reduction of kaolin suspension.

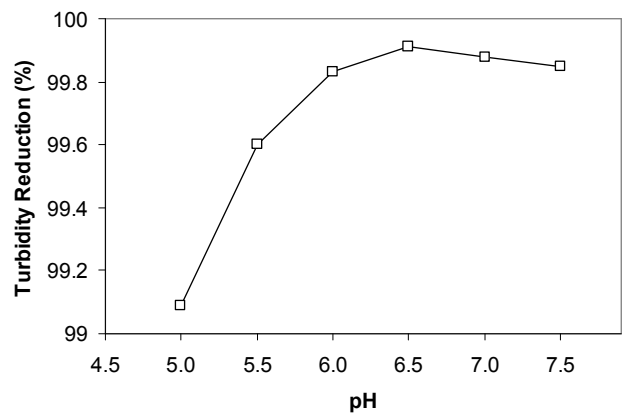

Fig 2. Effect of Ph (5.0 To 7.5) On Kaolin Turbidity Reduction Using Alcl $_{3}$-PAM Hybrid Polymer

Table 2. ANOVA Analysis of the Ph Effect on Turbidity Reduction

\begin{tabular}{cccccc}
\hline $\begin{array}{c}\text { Turbidity } \\
\text { Reduction }\end{array}$ & $\begin{array}{c}\text { Sum of } \\
\text { Squares }\end{array}$ & df & $\begin{array}{c}\text { Mean } \\
\text { Square }\end{array}$ & F & $\begin{array}{c}\text { Sig. (p- } \\
\text { value) }\end{array}$ \\
\hline Between Groups & 1.514 & 5 & 0.303 & 15.175 & 0.000 \\
Within Groups & 0.239 & 12 & 0.020 & - & - \\
Total & 1.754 & 17 & - & - & - \\
\hline
\end{tabular}

\subsubsection{Effect of $\mathrm{AlCl}_{3}-\mathrm{PAM}$ Hybrid Polymer Dosage}

The dosage of $\mathrm{AlCl}_{3}$-PAM hybrid polymer in flocculating kaolin suspension was varied to study the effect of $\mathrm{AlCl}_{3}$-PAM hybrid polymer dosage on turbidity reduction. The $\mathrm{pH}$ was kept at 6.5 as determined in previous section as the best $\mathrm{pH}$ in flocculating kaolin suspension. Effect of $\mathrm{AlCl}_{3}$-PAM hybrid polymer dosage on turbidity reduction is shown in Figure 3. Different dosage (1 to $6 \mathrm{mg} / \mathrm{L}$ ) of $\mathrm{AlCl}_{3}$-PAM hybrid polymer was used to flocculate kaolin suspension. The turbidity reduction was found to be increasing with the increase of dosage and achieved the highest reduction at $5 \mathrm{mg} / \mathrm{L}$ with an efficiency of $>99 \%$. The efficiency decrease after it achieved the highest turbidity reduction. This is probably due to the kaolin particles surface has been saturated with $\mathrm{AlCl}_{3}-\mathrm{PAM}$ hybrid polymer, further increase in $\mathrm{AlCl}_{3}$ PAM hybrid polymer dosage will contribute to the surface repulsion and leads to re-suspend of kaolin particles. ANOVA analysis is shown in Table 3. It was showed that there is a significant difference between dosages $(p<0.05)$. Hence, dosage is also concluded to be one of the vital factors that are affecting the flocculation efficiency.

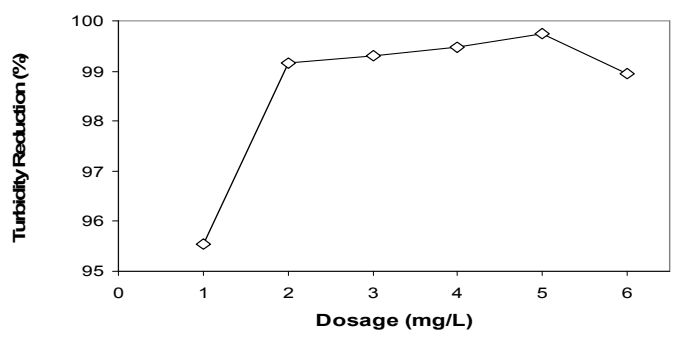

Fig 3. Effect of $\mathrm{AlCl}_{3}-P A M$ hybrid polymer dosage on kaolin turbidity reduction
Table 3. ANOVA analysis of the dosage effect on turbidity reduction

\begin{tabular}{cccccc}
\hline $\begin{array}{c}\text { Turbidity } \\
\text { Reduction }\end{array}$ & $\begin{array}{c}\text { Sum of } \\
\text { Squares }\end{array}$ & df & $\begin{array}{c}\text { Mean } \\
\text { Square }\end{array}$ & F & $\begin{array}{c}\text { Sig. (p- } \\
\text { value) }\end{array}$ \\
\hline $\begin{array}{c}\text { Between } \\
\text { Groups }\end{array}$ & 38.832 & 5 & 7.766 & 7.324 & 0.002 \\
$\begin{array}{c}\text { Within } \\
\text { Groups }\end{array}$ & 12.724 & 12 & 1.060 & - & - \\
Total & 51.556 & 17 & - & - & - \\
\hline
\end{tabular}

\subsubsection{Mechanism of Kaolin Flocculation}

The initial $\mathrm{pH}$ of the kaolin suspension was reported in the range of $3.49-4.29$. Kaolin surface charge was found by Basra et al. [9] appears to be negatively charged after $\mathrm{pH}$ 2.2. $\mathrm{OH}^{-}$ion was introduced into the kaolin suspension to adjust the $\mathrm{pH}$ to $5.0-7.5$ using $\mathrm{NaOH}$. Hence, the negative charge at the kaolin surface has been enhanced with the increase of $\mathrm{pH}$.

Eq. 2 is believed to be the mechanism of $\mathrm{AlCl}_{3}-\mathrm{PAM}$ hybrid polymer being ionized to become $\left[\mathrm{Al}^{3+} \cdot 3 \mathrm{Cl}^{-}\right]-\mathrm{PAM}$ when it was dosed into the kaolin suspension. The charge neutralization of the ionized $\left[\mathrm{Al}^{3+} \cdot 3 \mathrm{Cl}^{-}\right]-\mathrm{PAM}$ hybrid polymer with negatively charged kaolin surface $(\mathrm{SOH})$ took place and released $\mathrm{H}_{2} \mathrm{O}$ to the supernatant according to Eq.3. Eq. 3 is proved in Table 4 whereby the $\mathrm{pH}$ after flocculation was moving to neutral for fixed $\mathrm{pH} 5.0$ - 6.5 due to the release of $\mathrm{H}_{2} \mathrm{O}$ molecule into the supernatant [9, $10]$.

The overall surface chemistry equation of kaolin suspension and $\mathrm{AlCl}_{3}-\mathrm{PAM}$ hybrid polymer is shown in $\mathrm{Eq}$ 4. The further increase of $\mathrm{OH}^{-}$ion concentration after $\mathrm{pH}$ 7.0 will move the Eq 4 to left whereby the turbidity reduction will decrease as proved in Figure 2. Hence, the final $\mathrm{pH}$ will become higher than the fixed $\mathrm{pH}$ after the flocculation due to the excess $\mathrm{OH}^{-}$ion left in the supernatant. It is in agreement with the results shown in Table 4 where the final $\mathrm{pH}$ for fixed $\mathrm{pH} 7.0$ and 7.5 increase higher than fixed $\mathrm{pH}$ after the flocculation.

$$
\begin{gathered}
3 \mathrm{SOH}+\mathrm{AlCl}_{3}-\mathrm{PAM}+3 \mathrm{OH}^{-} \leftrightarrow 3 \mathrm{SOH}+\left[\mathrm{Al}^{3+} 3 \mathrm{Cl}^{-}\right]-\mathrm{PAM}+3 \mathrm{OH}^{-}(2) \\
3 \mathrm{SOH}+\left[\mathrm{Al}^{3+} 3 \mathrm{Cl}^{-}\right]-\mathrm{PAM}+3 \mathrm{OH}^{-} \leftrightarrow 3\left(\mathrm{SO}^{-}\right) \cdot \mathrm{Al}^{3+}-\mathrm{PAM}+3 \mathrm{H}_{2} \mathrm{O}(3)
\end{gathered}
$$

Overall,

$3 \mathrm{SOH}+\mathrm{AlCl}_{3}-\mathrm{PAM}+3 \mathrm{OH}^{-} \leftrightarrow 3\left(\mathrm{SO}^{-}\right) \cdot \mathrm{Al}^{3+}-\mathrm{PAM}+3 \mathrm{H}_{2} \mathrm{O}$

Table 4. Comparison of Supernatant Ph before and After Flocculation

\begin{tabular}{cc}
\hline Fixed $\mathbf{~ H}$ & $\mathbf{p H}$ after flocculation \\
\hline 5.0 & 5.96 \\
5.5 & 6.30 \\
6.0 & 6.78 \\
6.5 & 6.95 \\
7.0 & 7.30 \\
7.5 & 7.55 \\
\hline
\end{tabular}

\section{Conclusion}

$\mathrm{AlCl}_{3}$-PAM hybrid polymer of ratio of $1: 1$ has been successfully synthesized in this study using free radical polymerization method. Characterization of $\mathrm{AlCl}_{3}-\mathrm{PAM}$ 
hybrid polymer has been performed using Fourier Transform Infrared Spectrometer (FT-IR) to determine its functional groups in the hybrid polymer chain. It forms an inorganic-organic polymer complex. The $\mathrm{AlCl}_{3}-\mathrm{PAM}$ hybrid polymer was used in flocculating kaolin suspension. The $\mathrm{AlCl}_{3}$-PAM hybrid polymer was able to remove $>99 \%$ of turbidity at $\mathrm{pH} 6.5$ using a dosage of $5 \mathrm{mg} / \mathrm{L}$. The mechanism of kaolin suspension flocculation has been investigated in this study and $\mathrm{AlCl}_{3}$-PAM hybrid polymer has been shown to be an effective flocculating agent.

\section{Acknowledgement}

The authors wished to acknowledge the USM Fellowship provided by Universiti Sains Malaysia that has resulted in this study.

\section{References}

[1] M. Natalia, and D. Olli. Environmental Implications of Aggragration Phenomena: Current Understanding. Current Opinion. Colloid Interface Science. 2006, 11 (4): 246-266.

[2] P. Somasundaran, V. Runkana, and P.C. Kapur. Flocculation and Dispersion of Colloidal Suspensions by Polymers and Surfactants: Experimental and Modeling Studies. Coagulation and Flocculation H. Stechemesser and B. Dobias, Second Edition. Marcel Dekker. Taylor \& Francis. New York, 2005.

[3] Y. Wang, B.Y. Gao, Q.Y. Yue, J.C. Wei, J.C., and W.Z. Zhou, W.Z. Novel Composite Flocculent Polyferric Chloride-Polydimethyldiallylammonium chloride (PFCPDMADAAC): Its Characterization and Flocculation Efficiency. Water Practice \& Technology. 2006, 1 (3): 1-9.
[4] H. Tang, and B. Shi, B. The Characteristics of Composite Flocculants Synthesized with Inorganic Polyaluminium and Organic Polymers. In: Hermann H. Hahn, Erhard Hoffmann, Hallvard Odegaard (eds.), Chemical Water and Wastewater Treatment VII Proceedings of the $10^{\text {th }}$ Gothenburg Symposium. Gothenburg, Sweden. 2002, 17- 28.

[5] W.Y. Yang, J.W. Qian, and Z.Q. Shen, Z.Q. A novel flocculant of $\mathrm{Al}(\mathrm{OH})_{3}$-polyacrylamide ionic hybrid. Journal of Colloid and Interface Science. 2004, 273 (2): 400-405.

[6] K.E. Lee, B.T. Poh, N. Morad,and T.T. Teng, T.T. Synthesis And Characterization Of Hydrophobically Modified Cationic Polyacrylamide Prepared From Low Concentration Of Cationic Monomer. Journal of Macromalecular Science Part A. 2009, 46 (3): 240-249.

[7] H. Yokoi, T. Obita, J. Hirose, S. Hayashi, and Y. Taksaki. Flocculation Properties of Pectin in Various Suspensions. Bioresource Technol. 2002, 84 (3): 287-290.

[8] S.S. Wong, T.T. Teng, A.L. Ahmad, A. Zhairi, and G. Najafpour. Treatment of Pulp and Paper Mill Wastewater by Polyacrylamide (PAM) in Polymer Induced Flocculation. $J$. Hazard Mater. 2006, 135: 378-388.

[9] L. Besra, D.K. Sengupta, S.K. Roy, and P. Ay. Influence of polymer adsorption and conformation on flocculation and dewatering of kaolin suspension. Sep. Purif. Technol. 2007, 37 (3): 231-246.

[10] N. Tekin, O. Demirbas, and M. Alkan. Adsortion of cationic polyacrylamide onto kaolinite. Micropor. Mesopor. Mat. 2012,85 (3): 340-350. 